\title{
Ses ThelTLAS
}

\section{From Transdisciplinarity to Transdisciplinary Research}

\author{
Christian Pohl, td-net, Swiss Academies of Arts and Sciences, Berne, Switzerland, Department of Environmental \\ Sciences, ETH Zurich, Switzerland, Email: christian.pohl@scnat.ch
}

doi: $10.22545 / 2010 / 0006$

S cholars promote various definitions and concepts of transdisciplinarity in the current dialogue. The concepts can be described as alternative combinations of four characteristic features of transdisciplinarity, namely (a) to relate to socially relevant issues, (b) to transcend and integrate disciplinary paradigms, (c) to do participatory research, and (d) to search for a unity of knowledge. The meaning of transdisciplinarity in the GermanEuropean environmental and sustainability research shifted during the last decades, making feature (c) - to do participatory research - its major component. Against that background, td-net has developed and promoted a concept of transdisciplinary research that includes additional features. Formulated from the perspective of transdisciplinary researchers, our concept endeavors to frame, analyze, and process a socially relevant issue in such a way that the research project (1) grasps the complexity of the issue, (2) takes the diverse perspectives on the issue into account, (3) links abstract and case-specific knowledge, and (4) develops knowledge and practices that promote what is perceived to be the common good.

Keywords: transdisciplinarity, transdisciplinary research, transdisciplinary concept.

\section{Introduction}

A person who is interested in transdisciplinarity and able to connect to the Internet will probably look for the meaning of the term in Wikipedia. The joy of finding an entry might be transient, however, since the first thing(s)he reads is a warning that the neutrality of the article on transdisciplinarity is disputed, that it may contain original research or unverifiable claims, and even that the article may require a general clean-up to meet Wikipedia's quality standards. This is not because nobody engages in writing and reviewing the article - as the revision history shows - but because a number of scholars write new paragraphs and revise or delete old ones. For example, I did not find any of td-net's attempts to define the term when I visited the page a year after td-net had made contributions to the definition. This radical reviewing process indicates that the meaning of transdisciplinarity is contested among different schools of thought. The schools of thought (including the one I represent) are to some extent trying to impress their view on transdisciplinarity as the right one to the others.

The contested meaning of transdisciplinarity is relatively ironic for a community of scholars who sees the openness to other viewpoints as the fundamental prerequisite for doing transdisciplinarity [1-4]. You might think: "That is no problem for me; I am open to other viewpoints; I tolerate them." The point of openness and open encounters is, however, not to accept that there are other perspectives but to understand ones own viewpoint as a relative (in contrary to an absolute) one amongst many others. 
Giri refers to the philosopher R. Sunder Rajan to give an impression of what is needed to comprehend the relativity of one's own position:

"For Sunder Rajan, 'each perspective or point of view is such only as a member of a community of points of view (...). The problem with modern disciplinary thinking is that it fails to realise that its claim to universality needs to be relativised by recognising the significance of other disciplines in gaining multiple perspectives about the world to which both ones as well as another's discipline contribute. In this context, for Sunder Rajan, 'each discipline must shed an illusory universality to gain a perspectival universality' (...) The task here is to realise that the possibility of other perspectives is not merely a contingent or incidental feature but is essential to the very form of a perspective; a perspective is because it is one among others" [1]

Klein reminds us that transdisciplinary scholars - besides comprehending their relative perspective have to work with multiple perspectives. Therefore they need "not only the general capacity to look at things from different perspectives, but also the skills of differentiating, comparing, contrasting, relating, clarifying, reconciling and synthesizing" $[5]^{1}$. In the following, I will attempt to implement those skills. First, I will give a structured overview of concepts of transdisciplinarity. Then a summary will be given of the history of the idea of transdisciplinarity in the German-European environmental and sustainability research. Against that background, the definition we have developed and promoted within td-net will be presented. Finally, three core challenges for transdisciplinary research, based on how we conceptualize it, will be outlined.

\section{Concepts of Transdisciplinarity}

The fact that the meaning of transdisciplinarity is contested at least in the current Wikipedia-debate - does not imply that "anything goes." Rather, an analysis of current definitions of transdisciplinarity reveals two common patterns [4]. The first is that definitions of transdisciplinarity usually propose a

\footnotetext{
${ }^{1}$ In the quotation Klein originally refers to interdisciplinary individuals. In the context of the quotation Klein understands transdisciplinarity in the sense of [6] as strong integration (by one person). Interdisciplinarity on the other hand is a collective approach and therefore close to the understanding of transdisciplinarity presented in the present paper [5].
}

progression from multidisciplinarity through interdisciplinary to transdisciplinarity. It is a progression because every " $\mathrm{x}$-disciplinarity" goes further than the previous one in a specific aspect ${ }^{2}$. Jantsch [6] sees the progression in the degree of coordination within the whole education and innovation system. In transdisciplinarity, the whole system is oriented around an overall purpose like "progress" or "ecological balance." For Rosenfield [7], the progression lies in the shared conceptual framework. Interdisciplinarity means that researchers from different disciplines use their respective methods, techniques, and skills to address a common issue. Transdisciplinarity encourages representatives of different disciplines "to transcend their separate conceptual, theoretical, and methodological orientations in order to develop a shared approach to the research, building on a common conceptual framework." Lawrence sees the progression in the bodies of knowledge and societal groups involved: "Interdisciplinarity can be considered as the mixing together of disciplines, whereas transdisciplinarity implies a fusion of disciplinary knowledge with the know-how of lay-people" [8]. Hence, while the definitions share the idea of progression from multi- to inter- and transdisciplinarity, the definitions differ in the main feature of this progress.

The second common pattern the analysis of definitions revealed is that only a limited number of features are used to characterize transdisciplinarity. The features are (1) the focus on socially relevant issues, (2) transcending and integrating disciplinary paradigms, (3) doing participatory research, and (4) the search for a unity of knowledge beyond disciplines. In accordance with how they weigh these characteristics, the definitions can roughly be classified into three groups (see Table 1).

In concept $\mathrm{A}$, research becomes transdisciplinarity by transcending and integrating disciplinary paradigms in order to address socially (as opposed to academically) relevant issues. Transdisciplinary research is needed since the ongoing process of specialization of scientific knowledge production is driven by inner-scientific and disciplinary concerns, increasingly veering away from social problems and concerns. In a nutshell, Brewer puts this as "[t]he world has problems, but universities have departments" [9].

\footnotetext{
${ }^{2}$ This progress might be part of the rhetoric of definition rather than a factual necessity: "There is no inevitable progression form 'multidisciplinarity' through 'interdisciplinarity' to 'transdisciplinarity'" [5].
} 
Table 1: Three Concepts of Transdisciplinarity (A, B, C) as Combinations of

Four Features (based on [4]).

\begin{tabular}{|l|l|l|l|}
\hline \multicolumn{1}{|r|}{ Transdisciplinarity according to concept } & A & B & C \\
\hline Features of transdisciplinarity & & & \\
\hline Relating to socially relevant issues & & & \\
\hline Transcending and integrating disciplinary paradigms & & & \\
\hline Participatory research & & & \\
\hline Searching for a unity of knowledge & & & \\
\hline
\end{tabular}

The academic knowledge production, organized from a disciplinary perspective, has to be re-organized and re-assessed from the perspective of the socially relevant issue. Scholars representing concept A are Rosenfield [7], Jantsch [6] or Mittelstra [10].

According to concept $\mathrm{B}$, transdisciplinarity means to expand concept A by including non-academic actors (i.e. participatory research). By including non-academic actors, a discussion on knowledge production that was very influential in Europe is referred to. Gibbons et al. [11] and Nowotny et al. [12] identified a new mode of knowledge production, so called Mode 2. Mode 2 is supplementing the traditional linear model, within which "science proposes, society disposes"[13]. Mode 2-knowledge is produced in the context of the application of knowledge (in contrary to the academic ivory tower). The process of knowledge production includes stakeholders from science, civil society, and the private and public sector. To my understanding, for example Kötter [14], Scholz [15], Lawrence [8], and Mobjörk [16] are representatives of concept $\mathrm{B}$ of transdisciplinarity. The feature of participatory research is commonly not attributed to transdisciplinarity in the American context. Hence, Stokols [3] designates concept B of transdisciplinarity for the American context as "transdisciplinary action research." "Action research" stands for a participatory approach.
According to concept $\mathrm{C}$, research becomes transdisciplinary by adding the search for a unity of knowledge to concept A. The search for a unity of knowledge is not an end in itself. As with concept A, the overall aim is to reorganize the academic knowledge in order to make it useful for addressing socially relevant issues. In contrast to concept A, however, the knowledge is not re-organized and re-assessed in a pragmatic and eclectic way but by developing a general viewpoint or perspective beyond all disciplines. It is on the basis of such a fundamental viewpoint of knowledge beyond all disciplines that the socially relevant issues will be structured, analyzed, and processed in a second step. Nicolescu [17] and Ramadier [18] represent concept $\mathrm{C}$ of transdisciplinarity.

\section{Transdisciplinarity as a Concept in Flux ${ }^{3}$}

On the one hand, the concepts of transdisciplinarity promoted by individual scholars or schools of thought are rather stable. On the other hand, if you track the meaning of transdisciplinarity in a specific context - for example in the German-European environmental and sustainability research in the last

${ }^{3}$ This chapter draws upon chapter 11.2.1 of Bunders et al. [19] 
decades - the meaning of transdisciplinarity may shift. Transdisciplinarity becomes a concept in flux. The four features and the three concepts of transdisciplinarity (Table 1) are instrumental in tracing such a shifting meaning.

In Switzerland, transdisciplinarity was promoted by two initiatives of environmental research in the early 1990s: The scientific journal GAIA - Ecological Perspectives for Science and Society launched in 1991 and the "Swiss Priority Program Environment" initiated in 1992. The German philosopher Mittelstraß introduced concept A of transdisciplinarity in the editorial of the fifth issue of the first volume of GAIA:
"[T]ransdisciplinarity refers to knowledge or research that frees itself of its specialised or disciplinary boundaries, that defines and solves its problems independently of disci- plines, relating these problems to extra- scientific developments" $[20$, translated by Anne B. Zimmermann].

Since then, time and again, papers are published addressing transdisciplinarity as a concept or presenting transdisciplinary research in the field of environmental issues or sustainable development. Within GAIA, concept A of transdisciplinarity persists, as can be seen from GAIA's homepage: "[e]nvironmental problems cannot be solved by one academic discipline. The complex natures of these problems require cooperation across disciplinary boundaries." 4 The second promoter of transdisciplinarity was the "Swiss Priority Program Environment" (SPPE, 1992-2000), at that time the largest founding opportunity for environmental research in Switzerland with an overall budget of around 100 Mio USD. It was SPPEs program management that strongly promoted transdisciplinarity. SPPE was, on the part of the government, expected to help solve environmental problems through the program's research. The program managers considered transdisciplinarity instrumental to meet this expectation [21]. Toward the end of SPPE, the program's steering committee mandated two researchers interested in the management of inter - and transdisciplinary processes to elaborate criteria for evaluating inter and transdisciplinary research [22]. To develop criteria, they had to define what should be evaluated, i.e.

\footnotetext{
${ }^{4}$ http://www.oekom.de/etc/gaia, retrieved on November 2nd 2010.
}

transdisciplinarity. This definition shifted the meaning toward concept B of transdisciplinarity, stressing participatory research.

"Transdisciplinary research, in turn, here denotes interdisciplinary cooperation, involving not only scientists but also practitioners from beyond the realm of science (e.g., the users) in the research work." [22]

One reason for the shift was that SPPE was expected to contribute to social change with regard to environmental issues and including the "users and "practitioners"' seemed instrumental for that purpose. This shift toward concept B gained momentum at the program's closing conference, "Transdisciplinarity: Joint Problem Solving among Science, Technology and Society" [23]. Gibbons and Nowotny gave a keynote lecture on Mode 2 knowledge production, which takes place in the context of application, joins scientists and representatives of other societal sectors in the agora, and provides "socially robust knowledge" [23].

A number of European research programs on environmental and sustainability issues - like the Austrian programs "proVISION for nature and society" (2004-present) and "Transdisciplinary forms of research" (TRAFO, 2004-2007) and the German program "Social-Ecological Research" (SÖF, 1999present) - referred to and further developed SPPE's concept $\mathrm{B}$ of transdisciplinary research. In the early years of the new millennium, concept B - and specifically the feature of participatory research - gained still more momentum. In some of the research programs, transdisciplinarity even became synonymous with participatory research. Accordingly, one of the research programs states: "Transdisciplinary research [...] aims at participation of various groups of civil society, who are potential users of the research results, in the research process." ${ }^{5}$

\section{Transdisciplinarity as a Practice of Research}

In terms of transdisciplinarity as a concept in flux, concept B of transdisciplinarity - stressing participatory research as its key feature - dominated when td-net started working for the Swiss Academies of

\footnotetext{
${ }^{5}$ 5http://www.trafo-research.at, mission statement, retrieved on November 2nd 2010.
} 
Arts and Sciences in $2003^{6}$. Td-net was carrying on the work of sagufnet, a network for transdisciplinary research of the Swiss Academic Society for Environmental Research and Ecology (SAGUF) launched at the transdisciplinarity conference in 2000 [23]. The mission of td-net is to strengthen transdisciplinary research in all thematic fields, be it in research on peace, public health, sustainability, migration, and cultural diversity or on any other socially relevant issue. Amongst other activities, td-net organizes conferences to enable cross-field learning and publishes case studies and methodical and theoretical considerations on transdisciplinary research [24, 25].

The primary aim of td-net is to develop transdisciplinarity in the academic sector as a form of research. Our perspective on transdisciplinarity is that of a researcher asking him- or herself how to do transdisciplinary research. This does not imply that we see transdisciplinarity as a purely academic endeavor. It would be interesting to learn about the challenges of a transdisciplinary project as seen from the perspective of an actor of civil society or the private or public sector. And some might argue that it would be much more relevant to look at transdisciplinarity from a non-academic actors perspective. The decision of td-net was, however, to be primarily a network supporting researchers who engage in transdisciplinary endeavors.

This viewpoint implies a specific way of "defining" transdisciplinarity. It is not defined from the position of a detached observer who analyzes definitions of transdisciplinarity for its underlying specific features as in Table 1. The definition, rather, has to support researchers facing, for example, the issue of migration from Africa to Italy or the sustainable development of a touristic valley of the Swiss Alps. The question of researchers in such a situation is:

"What do I have to consider in my research to make a relevant contribution to the societal handling of the issue?" This leads us back to the purposes of integrating disciplinary paradigms, including social actors and developing overarching viewpoints, to develop a comprehensive understanding of the issue and to provide practical and useful knowledge. Tdnet's understanding of transdisciplinary research was developed against the background of the GermanEuropean environmental and sustainability research depicted above. This is why we took the aim of addressing a socially relevant issue as a starting point, in line with Wickson et al. who identified the problem focus-"the explicit intent to solve problems" [26]-as the first of three key characteristics of transdisciplinarity. In order to be relevant for problem handling, transdisciplinary researchers have to frame, analyze, and process an issue in such a manner that

1. they grasp the complexity of the issue,

2. they take the diverse perspectives on the issue into account,

3. they link abstract and case-specific knowledge, and

4. they develop knowledge and practices that promote what is perceived to be the common good [4].

From this perspective, three of the features of transdisciplinarity identified above - transcending and integrating disciplinary paradigms, participatory research, and searching for a unity of knowledge - are means that can be used to achieve the requirements (1)-(4). The requirements (1)-(3) are basics of the rationale for transdisciplinarity as a way to address social issues [27]. On the other hand, the promotion of the common good - or, more generally speaking, the evaluative component of transdisciplinary research - is rarely stated explicitly in definitions of transdisciplinarity even though an evaluative component is inevitable in order to know what an improvement of the current situation might look like. "The common good" here serves as a placeholder for underlying value systems in different thematic fields: "Peace" in peace research, "public health and well being" in public health research, "equality" in gender or cultural diversity research, or "sustainability" in research for sustainable development. Requirement (4) does not imply that one of the researchers (e.g. an ethician) or any another participant (e.g. a pastor) knows what the common good means in the projects specific context. Rather, one of the challenges for transdisciplinary researchers is to clarify underlying value systems by jointly developing the concrete meaning of, for example, sustainable development for the research projects specific context [28].

\footnotetext{
$\overline{{ }^{6} \text { www.transdisciplinarity.ch }}$
} 


\section{Consequences for the Practice of Transdisciplinary Research}

Requirements (1)-(4) result in a different overall design of the research process compared to a disciplinary research project. Three new challenges the researchers have to address are problem framing, integration, and bringing results to fruition (usually termed "implementation"). These challenges and ways to address them are further elaborated in [24] and in [4]. They are briefly outlined in the following section.

Problem framing. In a disciplinary research project, the problem is framed by disciplinary standards, such as the state of knowledge, methods, and theories (i.e. the disciplinary paradigm in Kuhn's terminology) [29]. In transdisciplinary research, researchers from different disciplines as well as actors form civil society and the private and public sectors are involved and perceive the issue from different perspectives. What is a pressing problem for one of them might not even be seen as a problem for somebody else.

The requirements of comprehending the issue in its complexity as well as taking into account the diverse perspectives call for a specific stage of collective problem framing. This stage is not common to recent research: funding agencies usually do not fund a stage of problem framing, and researchers do not apply for it. The few existing methods and approaches to problem framing often have an explorative character. Among those are the joint formulation of working hypotheses [30], a reformulation of the issue from the perspective of those who act [31] or methods that explore the different problem views by qualitative analysis [32-34] and interrelate them by means of dialogue methods.

Integration. Integration refers to the process of combining and reconciling research-and experience-based knowledge and perspectives of the academic and nonacademic participants. It is not like composing the pieces of a puzzle since the perspectives might not add to each other. This is because they are founded in different value systems and different ideas about what relevant knowledge is, how it can be gained, or what role science should play in social change [35]. With regard to complexity, the aim of integration is to achieve a more comprehensive and, with regard to power relations, a more balanced understanding of an issue and ways to handle it. Integration is seen as a core challenge of transdisciplinary research [36-40]. It may be more or less targeted to an overall synthesis. In a minor sense, integration refers to the mutual exchange of ideas and learning about different values and standpoints. Primarily, though, integration means jointly developing a shared theoretical understanding of the issue at stake. The task of integration cuts across the transdisciplinary research process, from problem framing through problem analysis to bringing results to fruition. Recently, scholars make first attempts to distinguish alternative approaches to integration [37, 40] and to develop and describe tools for [41] and methods of [42] integration.

Bringing results to fruition. Transdisciplinary research does not end with providing tailored knowledge to actors in civil society, the private sector, and public agencies. It calls for further engagement beyond making the results known and informing multipliers and key players. Referring to the terminology of Groß et al. [43], the stage of implementation, or to jointly work with non-academic actors in a transdisciplinary research project, can be seen as a real-word experiment, as an "experimental implementation" [44]. This means that implementation should be seen as an intervention in a social system and effects should be carefully observed with particular attention to surprises (unexpected effects). Surprises indicate that the assumptions, models, and explanations underlying the transdisciplinary research should be revised. New interventions can then be planned and conducted. To see the implementation as a realworld experiment is a means of reflection or getting reflective. This implies that the intended effect of a transdisciplinary research project becomes a subject of analysis and further development, too. This usually requires a long-term perspective of projects and project partnerships (up to several decades) as well as a recursive planning of the transdisciplinary research process, going back and forth between implementing, analyzing, developing new solutions, and perhaps re-framing the problem. Kiteme and Wiesmann [45] as well as Schelling et al. [46] provide exemplary case studies of such recursive, long-term transdisciplinary research processes.

\section{Conclusion}

In the world of Wikipedia, transdisciplinarity is a concept in flux. The meaning is contested and the debate open and not yet ready for closure. In an 
optimistic reading, this is an expression of an ongoing, lively debate among scholars, in a pessimistic reading, of a dispute about the right definition. Referring to requirement (2) of our understanding of transdisciplinary research - to respect the diversity of perspectives - I believe that we will not come up with a unifying definition but with a structured plurality of definitions. The present analysis suggests a structuring of definitions by clarifying their perspective - here researchers who conduct transdisciplinary projects, here the German-European environmental and sustainability research. If we go in that direction, we will further explore the meaning of Sunder Rajan's saying that "a perspective is because it is one among others" [1].

\section{Acknowledgements}

My thank goes to the team of td-net and to tdnet's advisory board, to the Swiss Academies of Arts and Sciences, to The Academy of Transdisciplinary Learning \& Advanced Studies, to the Swiss National Science Foundation, to the Competence Center Environment and Sustainability of ETH Zurich, to Gertrude Hirsch Hadorn, to Julie Klein and to all the colleagues and students who further developed my understanding of transdisciplinary research by their questions, remarks and suggestions for improvement.

\section{References}

[1] Giri, A.K., 2002. The Calling of a Creative Transdisciplinarity, Futures. 34, pp.103-115.

[2] Loibl, M.C., 2006. Integrating Perspectives in the Practice of Transdisciplinary Research. In: J.-P. Voß, D. Bauknecht, R. Kemp (Eds.), Reflexive Governance for Sustainable Development., Edward Elgar, Cheltenham, pp. 294-309.

[3] Stokols, D., 2006. Toward a Science of Transdisciplinary Action Research. Am J Commun Psychol, 38, pp. 63-77.

[4] Pohl,C., Hirsch Hadorn, G., 2007. Principles for Designing Transdisciplinary Research. Proposed by the Swiss Academies of Arts and Sciences, oekom Verlag, Mnchen.

[5] Klein,J.T., 1990. Interdisciplinarity. History, Theory, and Practice. Wayne State University Press, Detroit.
[6] Jantsch, E., 1970. Inter-Disciplinary and Transdisciplinary University - Systems Approach to Education and Innovation. Policy Sciences, 1, pp. 403-428.

[7] Rosenfield, P.L, 1992. The Potential of Transdisciplinary Research for Sustaining and Extending Linkages between the Health and Social-Sciences. Social Science \& Medicine, 35, pp. 1343-1357.

[8] Lawrence, R.J., 2004. Housing and Health: From Interdisciplinary Principles to Transdisciplinary Research and Practice. Futures, 36, pp. 487-502.

[9] Brewer, G.D., 1999. The challenges of Interdisciplinarity. Policy Sciences, 32, pp. 327-337.

[10] Mittelstraß, J., 1993. Unity and Transdisciplinarity. Interdiscipl Sci Rev, 18, pp. 153-157.

[11] Gibbons,M., Limoges, C. Nowotny,H., Schwartzman,S., Scott, P. Trow, M., 1994. The New Production of Knowledge-The Dynamics of Science and Research in Contemporary Societies. Sage, London, Thousand Oaks, New Delhi.

[12] Nowotny,H., Scott, P., Gibbons,M., 2001. ReThinking Science - Knowledge and the Public in an Age of Uncertainty. Polity Press, Cambridge.

[13] Guston,D.H., Sarewitz, D., 2002. Real-time Technology Assessment. Technology in Society, 24, pp. 93-109.

[14] Kötter,R., Balsiger, P.W., 1999. Interdisciplinarity and Transdisciplinarity: A Constant Challenge to the Sciences. Issues in Integrative Studies, 17, pp. 87-120.

[15] Scholz,R.W., Tietje, O., 2002. Embedded Case Study Methods. SAGE Publications, London.

[16] Mobjörk, M., 2010. Consulting versus Participatory Transdisciplinarity: A refined classification of transdisciplinary research. Futures, In Press, Accepted Manuscript.

[17] Nicolescu, N., 2002. Manifesto of transdisciplinarity. State University of New York Press, Albany.

[18] Ramadier, T., 2004. Transdisciplinarity and Its Challenges: The Case of Urban Studies. Futures, 36, pp. 423-439.

[19] Bunders, J.F.G, Broerse ,J.E.W., Keil,F., Pohl, C., Scholz,R.W.., Zweekhorst, M.B.M., 2010. How can Transdisciplinary Research Contribute to Knowledge Democracy?, in: R.J. in 't Veld (Ed.), Knowledge Democracy: Consequences for Science, Politics, and Media. Springer, New York, pp. 125-152. 
[20] Mittelstraß, J., 1992. Auf dem Weg zur Transdisziplinarität, GAIA, 1, p. 250.

[21] Öberli, R. H., Grossenbacher-Mansuy,W., 1998. Transdisziplinarität zwischen Förderung und berforderung. Erkenntnisse aus dem SPP Umwelt, GAIA, 7, pp. 196-213.

[22] Defila, R., Di Giulio, A., 1999. Evaluating Transdisciplinary Research, in: PANORAMA. Swiss Priority Programme (SPP), Environment, pp. 29.

[23] Klein, J.T., Grossenbacher-Mansuy, W. , Häberli, R., Bill, A., Scholz,R.W., Welti, M., 2001. Transdisciplinarity: Joint Problem Solving among Science, Technology, and Society. in: S.P.P. Environment (Ed.) Synthesebücher, Birkhäuser Verlag, Basel, pp. 332 .

[24] Hirsch Hadorn, G. , Hoffmann-Riem, H., BiberKlemm, S. , Grossenbacher-Mansuy, W., Joye, D. , Pohl, C., Wiesmann, U., Zemp, E., 2008. Handbook of Transdisciplinary Research. in: Springer (Ed.), Springer, Dordrecht.

[25] Darbellay, F., Paulsen, T., 2008. Le défi de l'Interet Transdisciplinarité - Herausforderung Inter- und Transdisziplinarität. Concepts, méthodes et pratiques innovantes dans l'enseignement et la recherche - Konzepte, Methoden und innovative Umsetzung in Lehre und Forschung, in, Presses Polytechniques et Universitaires Romandes (PPUR), Lausanne.

[26] Wickson, F., Carew, A.L., Russell, A.W., 2006. Transdisciplinary Research: Characteristics, Quandaries and Quality. Futures, 38, pp. 1046-1059.

[27] Lawrence, R.J., Desprs, C. , 2004. Futures of Transdisciplinarity. Futures, 36, pp. 397-405.

[28] Pohl, C., Rist,S., Zimmermann, A., Fry, P., Gurung, G.S., Schneider, F., Ifejika Speranza,C., Kiteme, B., Boillat, S., Serrano, E., Hirsch Hadorn, G., Wiesmann, U., 2010. Researchers' Roles in Knowledge Co-Production: Experience from Sustainability Research in Kenya, Switzerland, Bolivia and Nepal. Science and Public Policy, 37.

[29] Kuhn, T.S., 1996, The Structure of Scientific Revolutions. Third ed., University of Chicago Press, Chicago.

[30] Burkhardt-Holm, P., 2008. Fischnetz: Involving Anglers, Authorities, Scientists and the Chemical Industry to Understand Declining Fish Yields. in: Handbook of Transdisciplinary Research, Springer, Dordrecht, pp. 127-143.

[31] Hubert, B., Meuret, M., Bonnemaire, J., 2008. Shepherds, Sheep and Forest Fires: A Reconception of
Grazingland Management, in: Handbook of Transdisciplinary Research, Springer, Dordrecht, pp. 103126.

[32] R. Mabala, R, Allen. K.B., 2002. Bagamoyo College of Arts, Tanzania Theatre Centre, Participatory action research on HIV/AIDS through a popular theatre approach in Tanzania, Evaluation and Program Planning, 25, pp. 333-339.

[33] Hisschemller, M., Cuppen, E., Dunn, W.N., 2009. Stakeholder Dialogue as a Social Experiment. in: ESF workshop Mapping Interfaces: The Future of Knowledge, Reykjavik, Iceland.

[34] Ravnborg, H.M., Westermann, O., 2002. Understanding Interdependencies: Stakeholder Identification and Negotiation for Collective Natural Resource Management. Agricultural Systems, pp. 41-56.

[35] Elkana, Y. , 1979. Science as a Cultural Sytem: An Anthropological Approach. in: N. Bonetti (Ed.), Scientific Culture in the Contemporary World, SCIENTIA - International Review of Scientific Sythesis, Milano, pp. 269-290.

[36] Klein, J.T., 2008. Integration in der inter-und transdisziplinren Forschung, in: M. Bergmann, E. Schramm (Eds.), Transdisziplinäre Forschung. Integrative Forschungsprozesse verstehen und bewerten., Campus Verlag, Frankfurt/New York, pp. 93-116.

[37] Pohl, C., van Kerkhoff, L., Bammer, G., Hirsch Hadorn, G., 2008. Integration. in: Handbook of Transdisciplinary Research, Springer, Dordrecht, pp. 411-424.

[38] Jahn, T., Keil, F., Becker, E., Schramm, E., 2006. Transdisziplinäre Integration, in: E. Becker, T. Jahn (Eds.), Soziale Ökologie-Grundzöge einer Wissenschaft von den gesellschaftlichen Naturverhltnissen, Campus, Frankfurt/ New York, pp. 287-339.

[39] Bammer, G., 2005. Integration and Implementation Sciences: Building a New Specialization. Ecology and Society, 10.

[40] van Kerkhoff, L., 2005. Integrated Research: Concepts of Connection in Environmental Science and Policy. Environmental Science \& Policy, 8, pp. 452463.

[41] McDonald, D., Bammer, G., Dean, P., 2009. Dialogue Tools for Research Integration. in: ANU E Press, The Australian National University, Canberra, Australia.

[42] Bergmann, M., Jahn, T., Knobloch, T., Krohn, W., Pohl, C. , Schramm, E., 2010. Methoden transdisziplinärer Forschung: Ein Überblick mit Anwendungsbeispielen, Campus Verlag, Frankfurt/Main. 
[43] Groß, V, Hoffmann-Riem, V., 2005. Ecological Restoration as a Real-World Experiment: Designing Robust Implementation Strategies in an Urban Environment. Public Understanding of Science, 14, pp.269-284.

[44] van den Daele, W., Krohn, W., 1998. Experimental Implementation as Linking Mechanism in the Process of Innovation. Research Policy, 27, pp. 853-868.

[45] Kiteme, B.P., Wiesmann, U., 2008. Sustainable River Basin Management in Kenya: Balancing Needs and Requirements, in: Handbook of Transdisciplinary Research, Springer, Dordrecht, pp. 63-78.

[46] Schelling, E., Wyss, K.,Diguimbaye, C. , Bchir, M., Ould Taleb, M., Bonfoh, B., Tanner, M., Zinsstag, J., 2008. Towards Integrated and Adapted Health Services for Nomadic Pastoralists and their Animals: A North-South Partnership. in: Handbook of Transdisciplinary Research, Springer, Dordrecht, pp. 277-291.

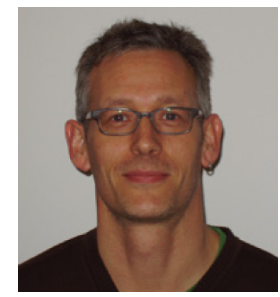

Dr. Christian Pohl is co-director of the transdisciplinarity-net of the Swiss-Academies of Art and Science and senior researcher and lecturer at the Department of Environmental Sciences at ETH Zurich. He was trained in environmental sciences and wrote a doctoral thesis on how to handle uncertainties in environmental assessments by using fuzzy sets. As a postdoc he moved to the field of science and technology studies, where he analyzed the collaboration of natural and social scientist in Swiss and Swedish policy-driven environmental research. In 2003 he became co-director of td-net for transdisciplinary research of the Swiss Academies of Arts and Sciences (http://www.transdisciplinarity.ch/e). Td-nets aim is to strengthen research that addresses real-world issues and for that purpose bridges academic as well as nonacademic expert knowledge. During the last years Christian Pohls work at td-net focused on the methodological particularities of transdisciplinary knowledge production. Out of this work he published, amongst others, the Principles for Designing Transdisciplinary Research (2007) and co-edited the Handbook of Transdisciplinary Research
(2008), both providing practical examples, theoretical basics and tools for collaborative knowledge production. Christian Pohls main field of research and publication is the analysis and design of transdisciplinary research, specifically in the field of sustainability sciences, and with a particular interest in the collaboration between natural and social sciences and the science-policy interrelation (http://www.envphil.ethz.ch/people/pohlc/index).

Copyright (c) 2010 by the author. This is an open access article distributed under the Creative Commons Attribution License (https://creativecommons.org/licenses/ by/4.0/), which permits unrestricted use, distribution, and reproduction in any medium, provided the original work is properly cited. 